\title{
Poder, un esbozo foucaultiano
}

\section{Luis Armando Durán Segura}

Profesor e investigador de la Universidad de Costa Rica. Costarricense. Bachiller y Licenciado en Antropología Social por la Universidad de Costa Rica. Magíster en Antropología y Magíster en Estudios Culturales por la Universidad de los Andes, Colombia. Doctorando en Estudios Latinoamericanos en la Universidad Nacional de Costa Rica. Correo electrónico: luarduse@yahoo.es

\author{
Recibido: Febrero 2014 • Aceptado: Mayo 2014
}

\section{RESUMEN}

El texto se encarga de realizar una breve síntesis de la noción de poder en algunos escritos de la prolija obra del filósofo francés Michel Foucault. Su intención es que las lectoras y los lectores no familiarizados cuenten con las herramientas básicas para afrontar el concepto, el contexto de su emergencia y desarrollo, así como sus aplicaciones recientes en el análisis social.

Palabras clave: poder, relaciones sociales, Michel Foucault, política.

\section{ABSTRACT}

The text makes a short summary of the concept of power in some writings in the extensive work of French philosopher Michel Foucault. The intention is that the unfamiliar reader acquires the basic tools to understand the concept, the context of its emergence and development and recent applications in social analysis.

Key works: power, social relations, Michel Foucault, politics.

...su pensamiento se servía de crisis y conmociones como condición creativa

Gilles Deleuze sobre Michel Foucault

Así como en sus mapas, sus intervenciones no ofrecen la garantía de éxito, ya que de cierta forma se encuentran ideológicamente en continua revisión. No se protegen de

lo aleatorio, de donde esas intervenciones nacen.

Michel de Certeau sobre Michel Foucault

En la medida en que el movimiento mismo del texto da cuenta admirablemente de lo que propone, la escritura de Foucault es perfecta: esa espiral generativa del poder, que ya no es una arquitectura despótica, sino un encadenamiento infinito, un enrollamiento y una estrofa sin origen ( sin desenlace tampoco), con un desplegamiento cada vez más vasto y más riguroso. Jean Baudrillard sobre Michel Foucault
Quienquiera que sea, o lo que sea, él es lo que le haría falta ser a cualquier sabio francés en la actualidad:

evasivo.

Clifford Geertz sobre Michel Foucault

No me pregunten quién soy y no me pidan que siga siendo el mismo.

Michel Foucault sobre su trabajo

\section{Anotación I}

¿Tiene alguna utilidad académica, política y social escribir unas cuantas líneas sobre las ideas de Michel Foucault en pleno año 2014? ¿Es oportuno rescatar su memoria justo en la fecha en que 
se conmemoran tres décadas exactas de su muerte? ¿Acaso no constituye esto una necia reiteración, una tentativa casi facsimilar a otras tantas, es simplemente un comentario más? En primera instancia sí. Habría de aclararse que, contundentemente, su obra está recubierta y saturada por lecturas sigilosas, interpretaciones críticas, reseñas anecdóticas, relecturas estridentes, apelaciones, interpretaciones, que aparecieron, aparecen y aparecerán en decenas de idiomas y desde infinidad de geografías.

Pero bien... "que se nos deje en paz cuando se trata de escribir" (Foucault, 1979: 30). El presente texto, que intenta ser un borrador o cuaderno de apuntes, rastrea anotaciones personales desperdigadas en libretas, archivos de computadoras y en reglones subrayados de las publicaciones del mismo autor francés. La escritura, lo debatía con frecuencia, termina siendo una tecnología para la experiencia, de desdoblamiento, recuento y transformación personal. Y en este caso, para reencontrar nociones que sirvieron como paraguas interpretativo en diferentes momentos y frente a diferentes fenómenos. "Escribir para ser otro" (Foucault, 1979: 30), una ritualidad que plasma el cambio, escribir para no ser el mismo, desfigurarse, modificarse.

\section{Anotación II}

No se tiene la intención de presentar acá un análisis absoluto, completo y sistemático de la obra de Michel Foucault, tarea titánica y quimérica de por sí. Por el contrario, y en un plano más terrenal, tiene como objetivo adentrar al interesado e interesada en sus tópicos políticos -en el sentido extendido- $\mathrm{y}$ en algunas de las posibilidades, alcances y matices de la categoría de poder. Esta postura de rastreo, razonablemente, es más asequible; no obstante, igualmente ardua. Dicho lo cual, conforma una suerte de introducción, una pequeña presentación de postulados que se pueden considerar como fuertes o centrales. ${ }^{1}$

Así, no trata de mostrar aspectos desconocidos de esos llamados y valorados como "novedosos", tampoco de ilustrar, educar o formar a un número determinado de lectores y lectoras neófitas. Todo lo opuesto. Es una suerte de maniobra provocativa para aquellas personas que no se han acercado al concepto, que en el contexto actual son, seguramente, muy pocas. Es incluso una suerte de "engaño" para quienes ya han caminado por esas ricas sendas, personas versadas en el tema, para que enciendan, retomen o recuerden.

\section{Apertura}

Conviene iniciar replicando que Michel Foucault fue el autor más citado del mundo entre 2007 y 2009 en tópicos sociales según los especialistas británicos de The Times Higher Education Guide, para vislumbrar su profunda influencia contemporánea, pero también para reconocer su estado de moda académica en el ámbito de las Ciencias Sociales y Humanas. En dicho ranking, aparece por encima de figuras tan determinantes y polémicas como Pierre Bourdieu, Albert Bandura, Erving Goffman, Max Weber, Karl Marx, Bruno Latour, Jürgen Habermas, Anthony Giddens y Judith Butler, entre otras, que estuvieron situadas en el podio de la "engalanada" y "distinguida" lista.

Al margen de la popularidad alcanzada globalmente, su porosa obra -traducida casi en su totalidad al español- se puede considerar como una de las más ricas del siglo $\mathrm{XX}$, no solo por

1. La iniciativa está precedida por algunos trabajos, bastante profundos, elaborados desde diversos flancos. Sobre el autor se ha dicho, se dice y se dirá mucho. Sin embargo, basta con revisar el desarrollo de la acepción foucaultiana de poder en algunos diccionarios-compendios de Filosofía (Castro, 2011 y 2004; Cortés y Martínez, 1996; Raynaud y Rials, 2001), Estudios Culturales y Críticos (Cousin y Hussain, 1984; Payne, 2002; Sardar, 2005; García, 2009), Antropología y Etnología (Kapferer, 2007; Moore, 2000; Bonte e Izard, 1996) y Sociología (Fernández, 2000; Campillo, 2002). Existen trabajos sobresalientes desde la perspectiva decolonial: Restrepo (2004), Castro-Gómez (2007) y la revista Tabula Rasa, número XVI (2012), que contiene un dossier con escritos de Ramón Grosfoguel, Monserrat Galcerán, Julia Suárez-Krabbe y otros y otras. 
sus aportes metodológicos, teóricos y conceptuales, sino también por su creatividad, criticismo y agudeza. La vida de este vasto pensador estuvo asociada, asimismo, con un permanente compromiso político frente a las exclusiones, separaciones y discriminaciones en la sociedad occidental y con el apoyo de las disidencias y pluralidades sexuales y eróticas. Estas intervenciones lo llevaron a desplegar una relevante actividad en los foros públicos, en los medios de comunicación y en las aulas universitarias.

Paul Michel Foucault nació en la comunidad de Poitiers (situada a 400 kilómetros al sur de París) en 1926, en el seno de una familia acomodada, hijo de un prominente médico de la región. Se licenció en Filosofía en 1948 y en Psicología en 1950, ambas en la École Normale Supérieure (Escuela Normal Superior de París). En 1961 leyó su tesis doctoral de Filosofía en la Universidad de Clermont-Ferrand, donde posteriormente ejerció la docencia. Desde mediados de la década de los cincuenta hasta mediados de la década de los sesenta, se dedicó a estudiar y explorar diacrónicamente las instituciones clínicas, el orden psiquiátrico y la locura. Folie et déraison (Historia de la locura en la época clásica) en 1961 y Naissance de la Clinique (El nacimiento de la clínica) de 1963 lo colocaron en los círculos de referencia. Se ocupó, en ese momento, de la construcción de la racionalidad europea-occidental y de lo otro (lo ajeno) que hallaba en su interior. Trabajos que le asignaron el apelativo de filósofo meticuloso y de estudioso del detalle.

A pesar de su formación, Foucault nunca se adscribió a ningún saber decimonónico delimitado, no se sintió cómodo definiéndose o colocándose en alguna grilla disciplinar y, en consecuencia, se rehusó tajantemente a ellas. Nunca fue un filósofo convencional (Strathern, 2014). Él mismo, con cierta frecuencia, sarcasmo y "mofa", señalaba el carácter indeterminado, fragmentario e hipotético de su trabajo, su renuencia a elaborar teorías acabadas y omniexplicativas, su horror por la totalidad (Castro, 2004: 5). Igual, se ocupó de temas dispares, por ejemplo, la literatura, el arte, el papel del autor, las epistemes de las ciencias naturales y la cultura helénica.

Se consideraba, más bien, un nómada transgresor de límites, que habitaba las fronteras y bordes de los saberes ortodoxos. Ser clasificado, prisionero de una ubicación y de una competencia, revestido de la autoridad que proporciona a los fieles su incorporación a una sapiencia, encasillado en una jerarquía de conocimientos y de lugares, era para Foucault, la figura misma de la muerte (de Certeau, 1998). Decía, por el contrario: “QQuién soy? Un lector”, afirmación de escape, utilizada curiosamente por J. L. Borges en muchas oportunidades. Fue un avergonzado por su posición legítima en el "orden del discurso" (Foucault, 2000), como lo expresó en la presentación de su sonada clase inaugural de 1970.

En 1966 publicó su obra más conocida, Les mots et les choses (Las palabras y las cosas), y se incorporó a la Universidad de Túnez, desde donde volvió a París atraído por los movimientos del año 68 , revueltas que influyeron a toda su generación. En 1969 apareció otro de sus libros claves, L'archéologie du savoir (La arqueología del saber), e ingresó un año más tarde en el Colegio de Francia, institución de referencia académica donde permaneció como profesor de Historia de los Sistemas de Pensamiento hasta su muerte en París en el año de 1984. Para la mitad de los años setenta, había publicado Surveiller et punir (Vigilar y castigar) y La volonté de savoir (La voluntad del saber), la primera parte de su Histoire de la sexualité (Historia de la sexualidad), que tuvo continuidad en L'usage des plaisirs (El uso de los placeres) y Le souci de soi (La inquietud de sí), de 1984. Luego, los cursos en el Colegio de Francia, trece en total, fueron recogidos como obras póstumas.

La arquitectura interna (cuadro 1) de la labor de Michel Foucault es siempre compleja de inventariar, catalogar y especificar por su variedad y constante autorrevisión; pero también, porque su trabajo se distinguía por promover y escarbar un "pensamiento de otro modo" (Deleuze, 1987). El propio autor no encontraba diferencias en su corpus teórico, no las notaba y se autodefinía 
CUADRO 1

Arquitectura básica de la obra de Foucault

\begin{tabular}{ccc} 
Periodización & Ontología histórica & Autodefinición intelectual \\
Arqueológico & La verdad y el saber & Arqueólogo de su propio pensamiento \\
Genealógico & El poder y los sujetos & Historiador de las problematizaciones \\
Ético/Estético & Moral y agentes éticos & Historiador del presente \\
\hline
\end{tabular}

Fuente: Elaboración propia.

como historiador de las problematizaciones ${ }^{2}$, o simplemente afirmaba que era un personaje sin rostro, un investigador histórico y político o un practicante de una historia del presente y de una ontología del presente.

Rabinow y Dreyfus (1988), por su parte, muestran que existen tres grandes fracturas en su pensamiento, dividiendo su obra por los objetos de investigación tratados: la verdad y el saber (1954-1970), el poder y los sujetos (1971-1978), la moral y los agentes éticos (1979-1984). Esta división concuerda con la clásica clasificación realizada a partir de sus métodos de estudio: periodo arqueológico (1954-1970), genealógico (19711978) y hermenéutico-ético/estético (1979-1984). Roger Chartier (2006) dice que fue arqueólogo de su propio pensamiento, siempre evaluando su producción, discursos y alusiones ${ }^{3}$.

\section{Los fuertes movimientos de la agenda posestructuralista francesa}

El posestructuralismo es sobre todo una heterogénea aproximación teórica al conocimiento y a la sociedad que acoge la incertidumbre de los

2. En palabras del autor se trataría de conseguir que sea cuestionado e interrogado todo aquello que se da por evidente, aquello que parece ser verdad absoluta y natural, aquello que se presenta como incuestionable, que no suscita dudas ni interrogantes, o que está en el olvido por ser tema indigno de la teoría clásica y que, por lo tanto, se presenta como aproblemático.

3. Otros estudios sobre las ideas de Foucault se pueden encontrar en Rabinow (1984 y 2003), Couzens (1988) y Blanchot (1992). significados, el poder constitutivo del discurso y la efectividad política de la teoría y la investigación. Se inició en la década de los sesenta como una tendencia dentro de la filosofía francesa, motivada inclusive por la crítica cultural del Mayo del 68. Posteriormente la aproximación migró hacia el mundo angloparlante, particularmente al estadounidense, donde tuvo un impacto transformativo en la filosofía, al igual que en los estudios literarios y culturales.

Resaltan los nombres de "glorificados" autores y autoras, discordantes muchas veces entre sí, como Jacques Lacan, Jacques Derrida, Gilles Deleuze, Felix Guattari, Roland Barthes, Jean-François Lyotard, Julia Kristeva y Jean Baudrillard. Estos y estas se concentraron en temas de intervención como el giro lingüístico y hermenéutico, las representaciones, el conocimiento, el deseo, el género y la sexualidad, y especialmente por el poder y la subjetivización. Arturo Escobar explica que se trata de una epistemología interpretativa y constructivista que, como punto de partida, critica la linealidad, la razón, la progresividad, el desarrollo, la no-simultaneidad y la no-ambigüedad (Escobar, 2005).

Aquellos filósofos y filósofas a quienes se llegaría a conocer como posestructuralistas confrontaron el proyecto estructuralista y modernista, tomando una actitud escéptica hacia la determinación por estructuras subyacentes y los intentos de encontrar la verdad última del lenguaje, la cultura, la sociedad y la psiquis, como sí lo habían pretendido Ferdinand Saussure, Claude Levi-Strauss, Karl Marx y Sigmund Freud, respectivamente. Los pensadores y las pensadoras estructuralistas, precedentemente, aducían el 
origen y la organización de fenómenos sociales complejos a estructuras más profundas ${ }^{4}$. Desvelar o descubrir esas estructuras era la tarea de la ciencia estructural (Gibson-Graham, 2002).

Por el contrario, en la discusión posestructuralista se encuentra en la desestabilización (en términos de intencionalidad), en el antifundamentalismo (en términos epistemológicos) y el antiesencialismo (en términos ontológicos) como paradigmas característicos de su teorización. En consecuencia, esta corriente se rehúsa a considerar el conocimiento como algo basado en la realidad o que estaba encargado de ser reflejo de ella. Nada de lo social es "natural" o "anterior" al discurso. Eduardo Restrepo y Axel Rojas (2010) apuntan que para el posestructuralismo la realidad se descifra como discursivamente constituida, lo que no quiere decir que sea solo un discurso.

No hay un concepto primario, fundamental o inmutable, sino que hay una infinidad de contextualizaciones que proveen lecturas múltiples y antagónicas de lo que es o puede ser algo o alguien. Para esta agenda de estudio, la creación de significado es un proceso inacabado, un sitio de constante forcejeo -político- donde se generan significados alternos y cuya firmeza es apenas temporal.

Precisamente, la influencia de Foucault sobre el posestructuralismo se ha concentrado en demostrar cómo las diferentes formas de poder están entrecruzadas con la producción de conocimiento para crear ciertas concepciones valorizadas en diversos periodos históricos (Strathern, 2014). Arguye:

4. Como caso paradigmático se tiene la obra de Claude Levi-Strauss (1977 y 1998), considerado el padre del estructuralismo científico. Este etnólogo francés tenía como objetivo fundamental la búsqueda de regularidades universales. Partiendo de un cerebro humano común para todas las culturas, el estructuralismo estaba interesado en los procesos de elaboración de dicotomías de la mente, a partir de las oposiciones binarias que canalizan la reflexión en cualquier sociedad. El estructuralismo defiende la idea de que un parecido extremo une en lo sustancial a todas las culturas, lo cual explica que esta orientación teórica se ocupe de las semejanzas entre las culturas antes que de las diferencias (Ortner, 1984).
Hay que admitir que el poder produce saber; que poder y saber se implican directamente uno al otro; que no existe relación de poder sin constitución correlativa de un campo de saber ni de saber que no suponga y no constituya al mismo tiempo relaciones de poder. (Foucault, 2002: 35)

Gracias a este autor, se entiende, pues, que el significado se produce bajo condiciones sociales e intelectuales específicas y que el conocimiento no es un reflejo verdadero, sino una fuerza productiva y constitutiva. Aunque los conocimientos no pueden ser diferenciados de acuerdo con un mayor o menor grado de precisión -su éxito o fracaso para reflejar el mundo-, sí pueden distinguirse por sus efectos -los diferentes sujetos a los que asienten dispositivos de poder, las instituciones y prácticas que permiten, al igual que aquellos que excluyen o suprimen. De esta forma, Foucault expuso cómo el tipo de conocimiento producido (poder/saber) -desde diversos extremos intelectuales- es un problema de consecuencia y no de indiferencia (Gibson-Graham, 2002).

\section{Anotación III}

Edgardo Castro (2012) sutilmente acierta cuando afirma que la analítica del poder para muchos autores y autoras provocó y provoca "anestesias y parálisis", especialmente en lo que respecta a la política, la acción y el compromiso. Basta leer las manifestaciones detractoras, sus apegos y reacciones.

Por un lado, y en lo estrictamente conceptual, la noción de poder resulta, para la crítica tradicional, paradójica, etérea, vaga, no metódica, ligera, pretensiosa y sin mucha cavilación. El concepto se les presenta como confuso, laxo, poco útil, nada explicativo y poco más que un curioso e infructuoso intento acaparador, es decir, nulo clarificador en términos académicos. Desde las disciplinas, principalmente, se ha censurado que no presente una diferenciación escalonada comprensible del poder y de su distribución, lo que no permite distinguir organizaciones diferentes.

Por otro lado, en la praxis, se le reclama al concepto cierto dejo apolítico; que se muestre 
abrumadoramente neutral, sin posición fija y nihilista en tonalidades peligrosas. Se dice frecuentemente que ata de manos y pies, sin posibilidad de acción concreta, directa e inmediata. Se dice, también, que carece de un programa estratégico, que no muestra un objetivo claro (a quién atacar, en qué momento, cómo hacerlo y con qué medios). Apelan a que involucra a todos y todas en el problema del poder, que no receta decálogos prácticos para salir a la calles, ni para protestar, ni para posibilitar reformas o cambios.

Como es evidente, estos malentendidos convertidos en opiniones desacertadas, se difunden desde los lugares autorizados para la representación y la manufactura del discurso, lugares que casi siempre tienen presunciones de linealidad, de esencias y absolutos, de la univocidad que debe tener la lucha social y la crítica universitaria, de la correspondencia y la correlación plena dentro de un sistema de pensamiento "correcto" y dentro de un orden previamente establecido.

Ahora bien, el concepto de poder efectivamente es ambivalente (tiene componentes oscilantes y hasta contrapuestos, tanto internos como externos, en disputa continua), y lo es, en sentido no peyorativo, porque encarna lo que el mismo poder es: ambivalente. Una intricada y densa urdimbre de relaciones que sostiene y posibilita acciones de montaje y, por qué no, de desmantelamiento. Un juego diario, pero histórico, una tensión, un estado de guerra permanente.

Las luchas, si se pueden llamar de esta manera, son fragmentarias y discontinuas para el autor; en otras palabras, son específicas. La analítica de poder no desactiva ni mina el sentido o la razón de ser de las luchas, como se argumenta desde flancos opositores. Estas, las luchas, están cargadas de pedazos de biografía y renuncian a explicaciones totales y, especialmente, a ser una opción puramente eficaz. Las luchas contra el poder pasan a otras trincheras, más desperdigadas de lo acostumbrado 5 .

\section{La noción foucaultiana de poder}

Poder es un nodo central por el cual transita la ocupación de Foucault. No es el único, evidentemente, pero sí el asunto de mayor articulación. Está presente tangencial y centralmente en sus diferentes discusiones, desde sus primeros escritos en la década de los cincuenta, hasta sus últimas obras en los ochenta. Empero, la noción misma de poder parece tener algunas considerables modificaciones a lo largo de sus textos. Aun así, su conceptualización es siempre de ruptura, según lo subraya Hindess (1996), constituye una “alternativa radical”. Por esto, fue quizás el más importante analista del poder -y de lo político en el amplio sentido del vocablo- en la segunda mitad del siglo XX (Fernández, 2002).

La entrada de sus análisis es diferente de la acostumbrada en muchos sentidos ${ }^{6}$. Su trabajo

5. Esta cuestión le lleva a preguntarse sobre la relación entre el intelectual, la teoría y lo político. Gilles Deleuze y Michel Foucault (2005) proponen, en una admirable conversación, que las relaciones teoría-práctica son condicionantes, pero a la vez parciales y fragmentarias, y no simples aplicaciones o relaciones de semejanza. La teoría serviría como una caja de herramientas, de donde se aprovechan los artefactos útiles para cada caso particular, por eso es que necesariamente es un aparato de combate. La teoría no expresaría, no traduciría, no aplicaría una práctica; en sí misma es una práctica, pero no totalizadora, sino local y regional. Es una lucha contra el poder, lucha para hacerlo aparecer y golpearlo donde es más invisible y más efectivo, porque desde su localidad, es una querella contra ciertos discursos y saberes. Por lo tanto, no se trata de decir la verdad desde la teoría, tampoco de representar a los aparentemente sin voz. El papel del intelectual, dicen los autores, no es el de situarse un poco adelante o un poco al margen para decir la muda verdad de todos (sucumbir en la indignidad de hablar por los otros); es ante todo luchar contra las formas de poder en donde este es a la vez el objeto y el instrumento de órdenes del saber, de las verdades y de los discursos que obstaculizan, prohíben e invalidan el habla de todos.

6. El texto clásico de Thomas Hobbes, El Leviatán de 1651, abre la tradición sustancialista, exponiendo que "el poder de un hombre (universalmente considerado) consiste en sus medios presentes para obtener algún bien material futuro" (1987: 69). El poder surge como la capacidad de realizar algo, requiriendo instrumentos para su adquisición y amplificación. En esta tradición sustancialista, de comprensión del poder, este aparece simplemente como algo de lo que se dispone o de lo que se carece (Fernández, 2000). 
dirigió la atención hacia las formas en que los conocimientos ejercen y producen poder -por medio de aparatos de regulación; por ejemplo, instituciones escolares, prisiones, ejércitos, casa de trabajo y fábricas en donde prevalecen las técnicas de disciplina y vigilancia corporal-, y mediante el desarrollo y aplicación de tecnologías para administrar el "ser" -por ejemplo, presupuestos, dietas, mapas, columnas de ayuda sexual, propagandas de productos de higiene personal-que motivan la organización de la vida diaria. Se dirigió a examinar la manera en que estos conocimientos y significados son normalizados y aceptados como verdad.

Esto abre literalmente la posibilidad de repensar el poder no escuetamente como fuerza represiva, es decir, como una instancia negativa, sino como una fuerza de avanzada productiva, por lo tanto positiva ${ }^{7}$. Esta operación analítica tiene varias implicaciones sobre el manejo de las relaciones de poder, centralmente, en: i) partir del

Esta concepción se extiende en el pensamiento del filósofo inglés Bertrand Russell, quien lo piensa como una sustancia que puede ser, entre otras cosas, transferida, repartida y suprimida. Argumenta el autor que "volviendo a la analogía de la física: el poder, como la energía, puede considerarse que pasa continuamente de una de sus formas a otra y debería ser tarea de la ciencia social buscar las leyes de esa transformación" (Russell, 1939: 11). Esta noción es retomada a mediados del siglo XX por la sociología funcionalista de Wright Mills (1980), especialmente en su elaboración de la suma cero.

La tradición sustancialista y positivista del poder encuentra, sin embargo, su primer opositor en Max Weber (1979), quien originalmente se preocupó por analizar las transformaciones de la modernidad y del Estado (Fernández, 2002). El autor mostró las legitimidades que se logran cuando los otros se desenvuelvan en la forma deseada a pesar de su probable resistencia. La definición de poder viene sucedida de "la probabilidad de imponer la propia voluntad, dentro de una relación social, aun contra toda resistencia y cualquiera que sea el fundamento de esa probabilidad" (Weber, 1979: 43). El concepto de poder, dice el autor, es sociológicamente amorfo. Todas las cualidades imaginables de un hombre y toda suerte de constelaciones posibles pueden colocar a alguien en la posición de imponer su voluntad en una situación dada (Weber, 1979: 43). acaecer, del cómo es que ellas operan, qué consecuencias tienen, qué interacciones establecen, qué acontecimientos franquean; y ii) posibilitar diferentes conceptualizaciones polemológicas, antisustancialistas, relacionales, concretas y no estáticas que de ahí se derivan.

Inicialmente esta noción de poder parte de un funcionamiento más que del decálogo categórico o de una definición "cincelada en piedra". El poder es entendido en la acepción foucaultiana como una característica inherente de las relaciones sociales, por más diversas que sean, que tienen lugar en el interior mismo de la sociedad, en su reproducción. Las relaciones de poder, por lo tanto, no son abstractas; por el contrario, son el resultado de relaciones de fuerza concretas que han surgido con ciertas peculiaridades en un momento histórico determinado.

El propio Foucault decía, sobre su elaboración, que no trataba de proponer principios, reglas y que ni a lo sumo se presentaba como la teoría general del poder; ya que para él no existen universales, más bien intrincamientos y yuxtaposiciones locales del poder. El poder para el autor no es una cosa, tampoco una sustancia, un fluido, algo que emana de esto y aquello; más bien, se trata de un conjunto de estrategias y mecanismos que tienen como objetivo lograr la victoria. El análisis de los tejidos del poder se abocaría entonces a "saber por dónde pasa la cosa, cómo pasa la cosa, entre quiénes, entre qué puntos, de acuerdo con qué procedimientos y con qué efectos" (Foucault, 2008: 14).

El poder no es algo que se posea (no es una institución, ni un régimen, ni es una estructura, aunque a veces se vale de ellas), sino acciones que se ejercen como prácticas de luchas, confrontación, negociación, acuerdos y desacuerdos entre actores y actrices sociales. Estos ejercicios componen una trama que colma la sociedad, pero que

7. Pensar las relaciones de poder en términos de represión, a Foucault (2001) le pareció insuficiente. Aún así, reconoció que todo lo que trabajó entre 1970 y 1976 podría inscribirse en ese marco de lucha-represión, postura que reelaboraría y abandonaría en los textos posteriores a 1977. 
nunca terminan de consolidarse por sus propias expresiones históricas, microsociales y cambiantes. El poder se disemina y pulula, pero también se diluye. Se entiende además, en esta perspectiva, que el poder no solo se limita exclusivamente a su carácter prohibitivo. En ocasiones, estas formas de privación se imbrican con formas de creación y producción de "cosas", por ejemplo de vida, de conductas, de cuerpos y de estéticas.

Para sintetizar esta postura, se presenta a continuación un punteo tentativo del tópico (Foucault, 1980, 1988, 1993, 1996a, 1996b, 2007, 2008). Para ello se fragmenta en siete postulados el tema, sin que esto signifique que se agote en estos simples rubros.

- El poder aparece con un carácter relacional. $\mathrm{Su}$ ejercicio consiste en conducir conductas; es decir, hay poder cuando un individuo o grupo actúa sobre las acciones de los otros, o sobre su campo de acción actual o eventual, ya sea presente o futuro. El poder no se posee, existe solo en su ejercicio. Es una estrategia ante otros y otras. El poder no es nunca lo que alguien tiene, sus recursos materiales o simbólicos, y tampoco lo que brota de alguien. No pertenece ni a una persona ni, por lo demás, a un grupo determinado; solo hay poder, porque hay articulaciones de gestión en relevos, dispersión, redes, apoyos recíprocos, diferencias de potencia, desfases, etcétera.

- El poder coexiste en todo el cuerpo social, lo traspasa e impregna. Está presente en la asimetría de relaciones vitales, al punto que puede empezar a funcionar en este sistema de diferencias. Siempre se está en el poder, no se puede estar fuera de él; lo que no significa que se esté atrapado en formas de dominación despóticas. El poder es, al fin y al cabo, una trama extendida, esparcida. Empero, no se trata del simplista retrato que argumenta que algunos detentan el poder y otros que lo sufren; inversamente, el poder nos involucra a todos, en zonas más densas y en otras más tenues, nadie es ajeno o está exento a esta trama.

- La lucha de clases puede, pues, no ser "la ratio" del ejercicio del poder. No obstante, la lucha de clases puede ser la garantía de inteligibilidad de algunas grandes estrategias. Esto va en detrimento de los postulados de marxistas dogmáticos. En esta terminología, el poder tampoco es una superestructura externa (meramente ideología) de la producción misma.

- Las relaciones de poder no obedecen exclusivamente a las formas de castigo. El poder negativo, por ejemplo, se ostenta en la obra freudiana y psicoanalítica en general. Para Foucault, por el contrario, el poder "hace", y no solo destruye, inflige, pena o castra. Disciplina, vigila y normaliza, en ocasiones sin el empleo de la fuerza física excesiva o corporal, logrando someter a los cuerpos y además a las conciencias. Consecuentemente, el poder subjetiviza y produce ciertas tipos de sujetos sociales, ciertas formas de ser/hacer/ ver en el mundo.

- El poder no se agota en lo jurídico y se extiende más allá de la política en sentido legislativo. Las relaciones de poder atraviesan los más íntimos y minúsculos campos de la vida y la cultura, tanto los interiores-privados como los exteriores-públicos; por lo tanto, el análisis de los mecanismos de poder sería insuficiente si explorara solo su aparato formal e institucional. El poder como una trama, compuesta de relaciones de relaciones, media las interacciones entre sujetos, entre objetos y entre ideas. Es una situación definitoria, pero nunca definitiva (Giavedoni, 2012). No se puede encontrar un anclaje único, ni sobredeterminante, solo plataformas volubles que lo eventualizan.

- Las relaciones de poder están inscritas de manera multiforme y diversa. El entrecruzamiento esboza hechos de captura, no en el sentido de una solitaria estructura binaria, dominador/dominados, poderoso/débil, sino en múltiples y heteromorfas relaciones. El poder es heterárquico, no una desnuda 
pirámide vertical (unos arriba que decretan y otros abajo que acatan), sino oblicuo, molecular. La vida social compuesta de diferentes cadenas de poder, funciona con lógicas distintas. No existe un nivel básico que gobierna sobre los demás, "sino que todos los niveles ejercen algún grado de influencia mutua en diferentes aspectos particulares y atendiendo a coyunturas históricas específicas" (CastroGómez, 2007: 170).

- No existen relaciones de poder sin resistencias. Estas últimas son más reales y trascendentes cuando se forman en el lugar exacto donde se ejercen las relaciones poder: el cuerpo, la codificación, la sexualidad, la ética, el espacio. Las resistencias no son meras rupturas accidentales, ni imágenes invertidas del poder, desafían sus múltiples centros; donde hay poder está su contrapartida, la resistencia. La resistencia, que solo aparece como acto, y como contraataque, es equivalentemente activa, inventiva, creativa, móvil, como lo es el poder. Si no acaecieran resistencias siempre, afirmó Foucault, no habría relaciones de poder. Todo sería simplemente una cuestión de obediencia absoluta. No obstante, como no hay un gran mandato, no hay un gran rechazo. Este aspecto es poco acabado por el autor; sin embargo, otros teóricos como Michel de Certeau (1996, 1999, 2007), José Giavedoni (2012), Reinaldo Giraldo (2009) y James Scott (2003) se han preocupado por darle continuidad al análisis de las resistencias cotidianas.

Revisada esta lista, se presentan en seguida dos de los más representativos y comentados ejercicios o técnicas de poder analizados por Michel Foucault.

\section{Política de/sobre la anatomía o anatomopolítica}

Vigilar y castigar (2002) fue animada en parte por el involucramiento del autor en el GIP (Grupo de Información sobre las Prisiones / Groupe d'information sur les prisons). En ella, estudia la metamorfosis de los métodos punitivos a partir de una tecnología política del cuerpo y se puede leer una historia común de las relaciones de poder y de las relaciones de objetualización. El texto se orienta sobre el cómo ciertas técnicas convierten al "hombre", el alma, el individuo normal o anormal- en objeto de intervención penal, y cómo un modo específico de sujeción ha podido dar nacimiento al "hombre" como objeto de saber para un discurso con estatuto científico (2002: 31). Muestra un desahogo tecnológico de la productividad del poder y con ello un cambio en la forma de concebir, manejar y controlar los espacios correccionales por parte de sus productores. Se trata ahora, dice Foucault, de disciplinar la sociedad. ${ }^{8}$

La sociedad occidental asiente el nacimiento de un acumulado de técnicas disciplinarias centradas en el cuerpo que producen efectos individualizantes y manipulan al mismo como foco de intervención. Estos, los cuerpos, deben hacerse útiles y dóciles. El poder toma literalmente al cuerpo como objeto de fuerzas con tecnologías de adiestramiento y corrección ${ }^{9}$. Por esto aparece, junto con la modernidad, el control de la actividad humana mediante el "arte" de las disposiciones espacio-temporales. Aunque estas no se limitan única y exclusivamente a las prisiones en sentido escrito, sino que abarcan también instituciones sociales como escuelas, ejércitos, fábricas y hasta hospitales.

Así, la disciplina procede a la distribución de los individuos en el espacio, y a su vez "organiza un espacio analítico" (Foucault, 2002: 147). El poder disciplinario establece una infrapenalidad; reticula un espacio que las leyes dejan vacío; mide, registra, examina, califica y reprime un conjunto de conductas que su relativa indiferencia hacía sustraerse a los grandes planes de

8. Posteriormente Gilles Deleuze (1995) anunció el paso de las sociedades disciplinarias a sociedades de control.

9. El sociólogo Richard Sennet (1999), quien empezó el proyecto de estudio del cuerpo con Foucault, realiza una historia paralela y alternativa a la expuesta. 
castigo (Foucault, 2002: 182). De la misma manera, propone nuevas conductas, nuevas formas de portar la anatomía, de sentirla y practicarla.

La disciplina se basa en técnicas minuciosas, con frecuencia ínfimas, no en vano importantes, puesto que definen cierto modo de adscripción política y detallada del cuerpo, una nueva microfísica del poder. Las técnicas no han cesado, desde el siglo XVII, de invadir dominios cada vez más amplios y han tendido a cubrir el cuerpo social entero (Foucault, 2002: 142). Estos pequeños ardides, conferidos de una gran capacidad de expansión, han provocado la transformación del régimen punitivo en el umbral de la época contemporánea. Para ellos, los productores del espacio, se privilegia el nacimiento y la reproducción de un discurso urbanístico (Rabinow, 2004). El poder se inscribe claramente en el diseño del espacio arquitectónico para asegurar la vigilancia y la normalización.

Colocando la dimensión espacial como dimensión activa provoca una inflexión con las visiones historicistas lineales (Foucault, 1986). La reflexión de las espacialidades se incita con el argumento de que:

podría escribirse toda una historia de los espaciosque sería a la vez una historia de los poderes-, desde las grandes estrategias de la geopolitica hasta las pequeñas tácticas del hábitat, de la arquitectura institucional, del salón de clase o de la organización hospitalaria, pasando por las implantaciones económico-politicas. (Foucault, 1980: 5)

Precisamente, la tecnología de poder disciplinario se maximiza a finales del siglo XVIII con la incorporación del panóptico en la arquitectura carcelaria; fórmula establecida por el filósofo inglés Jeremy Bentham, que substituyó la oscuridad del calabozo medieval por la novedosa luminosidad, tratando de hacer transparente cada movimiento, por pequeño que fuera para interrogarlo y sistematizarlo, de personajes aparentemente "dominados". Esta invención, en primer lugar, compone una maquinaría social que disocia la pareja "ver-ser visto" (Foucault, 2002: 205).
El beneficio y utilidad son método de ejecución: un solo vigilante se hacía cargo de toda la prisión; instalado en el centro del espacio construido, lograba advertir las acciones de todos los penados sin que ellos lo pudieran mirar a él, pero estando conscientes de su presencia. En esta disposición el poder no solamente oprime al oprimido, sino que también afecta al sujeto opresor. Todos los que trabajan dentro de estos sistemas, incluido el vigilante en su torre, están ligados a una compleja red de conciencias.

Precisamente, la sombría mazmorra de la premodernidad, donde se cometían atroces torturas, ha sido reemplazada por la moderna prisión, intensa y brillante, basada en el encuentro de luces; pero Foucault advierte que "la visibilidad es una trampa" (Foucault, 2002: 2005). Por medio de esta vigilancia ocular, la sociedad moderna ejercita sus sistemas de control, de poder y de conocimiento. El autor sugiere que dentro de todos los niveles de la sociedad moderna existe un tipo de prisión continua, un pequeño teatro. Todo está conectado por la vigilancia (deliberada o no) de unos seres humanos por otros.

En resumen, se debe entender el arquetipo panóptico, o más bien el panoptismo, "como un modelo generalizable de funcionamiento; una manera de definir las relaciones del poder con la vida cotidiana de los hombres" (Foucault, 2002: 208). Gracias a las técnicas de vigilancia, óptica y panóptica, se efectúa un juego de miradas que asegura la intervención, sin recurrir en principio, al exceso, a la fuerza y a la violencia. Se llega a los cuerpos con la profundidad de la imágenes (facilitar cuerpos sumisos y productivos) persiguiendo el adiestramiento repetitivo, minucioso y concreto de las fuerzas racionales. Toda una ortopedia social. Estos tres aspectos del panoptismo -(auto)vigilancia, (auto)control y (auto)corrección-constituyen una dimensión prototípica, fundamental y característica de las relaciones de poder que existen en el mundo coetáneo ${ }^{10}$.

10. Avances en el tema de vigilancia e hipervisualidad se pueden encontrar en el trabajo de Guy Debord (1999), Paul Virilio (1999) y Comaroff y Comaroff (2009). 


\section{Política de/sobre la vida o biopolítica}

Michel Foucault, sin duda, abrió un prometedor campo de experimentación conceptual al señalar que el objetivo primordial del poder ello forma parte de la diatriba- no es otro que el control, la creación/destrucción y la gerencia de la vida en cada uno de sus estratos, variaciones, singularizaciones y modos de efectuarse. ¿Qué debe entenderse por vida y ser viviente, y cómo el poder delimita, condiciona o facilita incluso la emergencia y el despliegue de la vida misma? Para desentrañar algunos de los problemas derivados de esta postulación interrogativa, se debe repasar la alteración que realiza el filósofo de un aforismo condicionante.

Las posibilidades del entendimiento de las complejas tramas del poder aparecen relacionadas directamente con dicha inversión retórica. La mutación parte de que, en la soberanía monárquica, el Rey tenía el derecho tanatológico de ordenar la muerte: "el soberano no ejerce su derecho sobre la vida sino poniendo en acción su derecho de matar, o reteniéndolo: no indica su poder sobre la vida sino en virtud de la muerte que puede exigir" (Foucault, 1996a: 164). Al respecto afirma que, en un momento iniciático, se trata del "derecho de hacer morir y dejar vivir" (Foucault, 1996a: 166).

Ahora bien, el biopoder introduce un cambio en la manera en que se despliega el poder, ya no de un derecho de muerte, sino de una maximización de la vida:

...por primera vez en la historia, sin duda, lo biológico se refleja en lo político; el hecho de vivir ya no es un basamento inaccesible que sólo emerge de tiempo en tiempo en el azar de la muerte y su fatalidad; pasa en parte al campo de control del saber $y$ de intervención del poder. (Foucault, 1996a: 172)

Si con el derecho del soberano se trataba de "hacer morir y dejar vivir", en el biopoder se instala el nuevo derecho, inverso, "de hacer vivir y dejar morir" (Foucault, 1996a: 167). En fin, un vehemente poder surgido durante el siglo XVIII.

Foucault (2001) dice que no solo se reemplazó la muerte como castigo contra el delito, sino que además se apostó por la vida como unidad a maximizar, multiplicar, fortalecer. Ella, la vida, que anteriormente era tenida en cuenta por el poder únicamente en aras de su eliminación, pasó a ser el escenario sobre el cual iba a ejercer control potenciador. El derecho de muerte entonces tuvo que acoplarse a las exigencias orgánicas que dispusieran de la supervivencia y conservación. Se yuxtaponen la relación disciplinaria y la reguladora y las relaciones vitales.

No hay continuación lineal entre el poder disciplinario (anatomopolitica), que se refiere al poder ejercido sobre el hombre-cuerpo individualizado, dócil y útil (Foucault, 2002), y entre lo biopolítico, que se refiere al hombre-viviente, por lo que se centra en varios aspectos, objetos o campos que le atañen como especie. Dice:

...una tecnología del poder que no excluye la primera [disciplinaria] sino que la engloba, la integra, la modifica parcialmente $y$, sobre todo, que la utilizará implantándose en cierto modo en ella, incrustándose, efectivamente, gracias a esta técnica disciplinaria previa. (Foucault, 2001: 219)

A pesar de esto, Foucault se preocupa por diferenciar los rasgos del poder disciplinario y los rasgos del biopoder. Este último no actúa sobre el cuerpo como unidad, sino sobre un cuerpo compuesto y variado. El poder biopolítico se diferencia del primero -disciplinario- en cuanto se trata de un efecto de estandarización y regularización regional. Ya no adiestra personalmente, sino que establece mecanismos con miras a eventualizar una estabilidad biológica, un equilibrio. La atención, centrada en la vida, se dirige hacia un nuevo objeto que es definido por el autor como la población: "se trata de un nuevo cuerpo: cuerpo múltiple, cuerpo de muchas cabezas, si no infinito, al menos necesariamente innumerable" (Foucault, 2001: 219).

La vida dejó de ser un campo neutro, desconocido, compartido por todas y todos en el cual nunca se ponía en juego la política; antipodalmente, se tornó como objeto de intervención e instrumentalización por parte de las técnicas. Por supuesto, dicho poder no capturó la vida 
objetivamente como un elemento que le fuera extraño. En tanto objeto de conocimiento, ejerció control sobre ella y la produjo, o de forma tautológica si se quiere, la produjo para ejercer control sobre ella posteriormente. Lo que llama Foucault (2001) la entrada de la vida en la historia permite que, en el ámbito político, se determine qué es vivir y cómo y cuándo se vive. En esto radica el paso del poder soberano al biopoder ${ }^{11}$.

\section{Anotación IV}

Obviamente el alcance y la complejidad del concepto de poder no se limita a lo anteriormente mencionado. Este se extiende ricamente en diversos campos del saber social como la historia, la arquitectura, el urbanismo, la pedagogía, la lingüística, la antropología, las relaciones internacionales, la sociología, la criminología, la anitpsiquiatría y la psicología crítica. Implicaciones que riegan el pensamiento actual. Su influencia se puede mapear a través de la recepción de sus textos en los estudios políticos, en los estudios feministas, de género y de la sexualidad, en los estudios sobre identidad y etnicidad. También, en los estudios subalternos y poscoloniales, la crítica etnográfica, los estudios sobre el cuerpo y las subjetividades y los análisis sobre la violencia, que emplean las cavilaciones de tal corriente.

\section{Cierre}

Este texto ha intentado poner en relieve modestamente claro está- algunas características diferenciales del concepto de poder en las investigaciones de Michel Foucault. Es obvio que el trabajo del autor es cualitativa y cuantitativamente más extenso que lo expuesto. Se intentó

11. Avances divergentes en el tema de biopolítica se pueden encontrar en la obra de Agambem (2003 y 2006), Esposito (2006), Duncan (2007), Osorio (2012), Stoler (1995) y Ugarte (2005); compilatorios de Giorgi y Rodríguez (2007), Lemm (2010), Arribas, Cano y Ugarte (2010); y en América Latina los estudios de Castro Gómez (2008 y 2010), Pedraza (2004a y 2004b) y Arias (2013). provocar e invitar a la lectura de esta voluminosa producción, que a pesar de estar troceada por las editoriales y casas de publicación, es relativamente accesible. Producción que se exterioriza como una referencia ineludible para entender los nuevos lugares de "lo político" (Balandier, 1994). El efecto viral y el carácter masivo de sus propuestas han beneficiado y empapado los debates de muchas corrientes. No en vano, en estas tres últimas décadas su figura ha adquirido, en los Estados Unidos y América Latina, un renombre equiparable a los sensacionales héroes de la mitología "hollywoodense" (Cusset, 2005).

Sobre la creación foucaultiana, Castro afirma que:

...nada más alejado de las intenciones de Foucault que elaborar una teoría política para decirle a la gente lo que debe pensar o hacer, deduciendo estas prescripciones de una visión general acerca del curso de la historia o de su destino inevitable. Al contrario, sus investigaciones acerca del poder son análisis específicos (sobre las prisiones o el sistema médico, por ejemplo) que buscan establecer aquellos puntos de ruptura donde antiguas prácticas cumplen nuevas funciones o donde surgen y se articulan nuevas prácticas, y que son, al mismo tiempo, los lugares en los que la acción política puede resultar. (2012: 23)

El poder, se ha revisado, es algo considerablemente complejo, pero a la vez concreto y efectivo. No es el burdo reflejo del poder estatal, de la economía o del mercado; tampoco es reductible a la función perversa de la negación, pues estas son formas límites o acopladas de este. El poder no solo constriñe, sino que también origina: ocasiona efectos de verdad y produce saberes. Por tal razón, las relaciones de poder están siempre surcando todo el cuerpo social, sosteniéndolo, produciéndolo y recreándolo: no como un gran leviatán, a la manera hobbesiana, sino como un conjunto de dispositivos ejercibles y ejercitados, una situación estratégica definitoria, pero nunca definitiva, que hay que analizar para deducir de qué manera funcionan, qué efectos producen, cuáles son sus discursos y cuáles son sus prácticas.

Primero, la técnica disciplinaria o anatomía política, que se identifica por ser una tecnología 
individualizante del poder, se basa en la inspección de los individuos, sus comportamientos y sus cuerpos con el fin de anatomizarlos, es decir, crear cuerpos máquinas, mansos y desintegrados. Está apoyada en la disciplina como instrumento de control del cuerpo social, penetrando en él hasta llegar hasta sus partes más chicas: las partículas, las células, las moléculas. La cautela, la intensificación del rendimiento, la multiplicación de capacidades, la repetición, el emplazamiento y la utilidad son algunas de sus características. Por eso las cárceles, los ejércitos, los hospitales y las aulas presentan similitudes.

Se concuerda con García Canal cuando muestra que el poder disciplinario:

...se arraiga, adquiere peso, volumen, consistencia; se inscribe en los cuerpos, diseña muros y fronteras, se implanta en el suelo, marca su territorio: tiene la materialidad de una fuerza, adquiere visibilidad. Espacio y poder se entrelazan, no pueden ya ser comprendidos fuera de este indisoluble vínculo, donde las relaciones de poder actuantes en un espacio le otorgan a éste movimiento, vida, dinamismo; preconizan y exigen continuas transformaciones, nuevas distribuciones, nuevas maneras de organización y expresión. Le dan su sello y carácter. (2006: 72)

Segundo, que el grupo de técnicas que conforma el biopoder, tiene como objeto las poblaciones humanas, la especie, las masas, multitudes y grandes colectivos, grupos de seres vivos regidos por procesos y leyes biológicas y, por razones obvias, vitales. De la biopolítica devienen marcos informativos; industrias de seguridad, racismo y gubernamentalidad; coacción etaria y sexual; tasas y estadísticas conmensurables de natalidad, alimentación, belleza, mortalidad, medicación y morbilidad; nuevos parámetros para el erotismo; prácticas urbanísticas, salubristas e higienistas fundadas en los modelos de pestes-plagas-monstruos; abstracciones noso-políticas; movilidades extendidas/limitadas en los territorios; guerras exploratorias, entre muchos otros, que pueden vincularse para mediar la vida en la dirección que se desee (Ibarra, 2008). A partir en el intersticio de lo biológico, en esa faja entre lo inmanente, lo biológico y lo político, las tecnologías modernas intervienen y colonizan de un modo nuevo.

\section{Anotación V}

Michel Foucault es ya un clásico del siglo $\mathrm{XX}$. Lo es en toda regla y en plenitud de condiciones. Es una veta casi inagotable de materiales. De la curiosa lista que realiza Italo Calvino en Por qué leer los clásicos se pueden emplear, con varios grados de ímpetu, ocho características para redefinirlo:

" $V$. Toda lectura de un clásico es en realidad una relectura.

VI. Un clásico es un libro que nunca termina de decir lo que tiene que decir.

VII. Los clásicos son esos libros que nos llegan trayendo impresa la huella de las lecturas que han precedido a la nuestra, y tras de sí la huella que han dejado en la cultura o en las culturas que han atravesado.

VIII. Un clásico es una obra que suscita un incesante polvillo de discursos críticos, pero que la obra se sacude continuamente de encima.

IX. Los clásicos son libros que cuanto más cree uno conocerlos de oídas, tanto más nuevos, inesperados, inéditos resultan al leerlos de verdad.

XI. Tu clásico es aquel que no puede serte indiferente y que te sirve para definirte a ti mismo en relación y quizás en contraste con él.

XIII. Es clásico lo que tiende a relegar la actualidad a categoría de ruido de fondo, pero al mismo tiempo no puede prescindir de ese ruido de fondo.

$X I V$. Es clásico lo que persiste como ruido de fondo incluso allí donde la actualidad más incompatible se impone". (Calvino, 1993: 7-13)

También es elemento sagrado, una "deidad" en las disciplinas sociales y humanas. Un aparato a prueba del tiempo, que se reinventa y que rehúye a flamantes censuradores. Se santifica, ensalza, se discute y apropia; se revive diariamente; se convoca en divulgaciones escritas y audiovisuales, en charlas, coloquios y conversatorios. Su distintiva 
imagen (suéter monocromo de cuello alto, ocasionalmente abrigado con una chaqueta de cuero o un saco mediamente formal, lentes y cabeza afeitada) se volvió objeto de consumo e idolatría.

Maquinando, ficcionalmente, dicha denominación lo atormentaría como ninguna otra categoría lo habría hecho antes. Ser un clásico, recubierto de dogma y portador de un aura, molestaría e irritaría irremediablemente al "hombre" que evitaba tener un rostro, una identidad unívoca o una oficialidad.

\section{Referencias bibliográficas}

Agamben, Giorgio (2003). Estado de excepción. Valencia: Pre-textos.

Agamben, Giorgio (2006). Homo Sacer I. El poder soberano y la nuda vida. Valencia: Pre-textos.

ArIas, Denis (2013). Criaturas de lo heroico y lo monstruoso. Metáforas del saber biopolítico y sus cuerpos (Costa Rica, 1900-1946). Tesis Doctoral en Historia. Universidad Libre de Berlín.

Arribas, Sonia, Cano, German y Ugarte, Javier (2010). Hacer vivir, dejar morir. Biopolitica y capitalismo. Madrid: La Catarata.

BALANDIER, Georges (1994). El poder en escenas: de la representación del poder al poder de la representación. Madrid: Paidós.

Blanchot, Michel (1992). Michel Foucault, tal y como lo imagino. Barcelona: Pre-Textos.

Bonte, Pierre e Izard, Michael (1996). Diccionario Akal de Etnología y Antropología. Madrid: Akal.

Calvino, Italo (1993). Por qué leer los clásicos. Barcelona: Tusquets.

CAmpillo, Antonio (2002). “El 'sueño antropológico' y la historia de la subjetividad”. En: Prior, Ángel (coord.), Nuevos métodos en ciencias humanas (pp. 61-80). Barcelona: Anthropos.

Castro-Gómez, Santiago (2007). "Michel Foucault y la colonialidad del poder”. Tabula Rasa, 6(1): 153-172.

CAstro-Gómez, Santiago (2008). La hybris del punto cero. Bogotá: Editorial Pontificia Universidad Javeriana.

Castro-Gómez, Santiago (2010). "Siglo XVIII: el nacimiento de la biopolítica”. Tabula Rasa, 12 (1): 31-45. Universidad Colegio Mayor de Cundinamarca.
CAstro, Edgardo (2004). El Vocabulario de Michel Foucault. Buenos Aires: Prometeo.

CASTro, Edgardo (2011). Diccionario Foucault: temas, conceptos y autores. Buenos Aires: Siglo Veintiuno.

CAstro, Edgardo (2012). Michel Foucault. El poder, una bestia magnífica. Buenos Aires: Siglo Veintiuno.

Chartier, Roger (2006). Escribir las prácticas. Foucault, de Certeau, Marin. Buenos Aires: Ediciones Manantial.

Comaroff, Jean y Comaroff, John (2009). "Obsesiones criminales después de Foucault: poscolonialismo, vigilancia policial y metafísica del desorden". En: Violencia y ley en la poscolonia: una reflexión sobre las complicidades Norte-Sur (pp. 67-131). Barcelona: Katz.

Cortés, Jordi y Martínez, Antoni (1996). Diccionario de Filosofia. CD-ROM. Barcelona: Herder.

Cousin, Mark y Hussain, Athar (1984). Michel Foucault. Londres: Macmillan Publishers Limited.

Couzens, David (ed.) (1988). Foucault. Buenos Aires: Ediciones Nueva Visión.

Cusset, François (2005). French Theory. Foucault, Derrida, Deleuze \& Cía. y las mutaciones de la vida intelectual en Estados Unidos. Barcelona: Editorial Melusina.

De Certeau, Michel (1996). La cultura en plural. Buenos Aires: Nueva Visión.

De Certeau, Michel (1998). "La risa de Foucault". En: Historia y Psicoanálisis. México: ITESO.

De Certeau, Michel (1999). La invención de lo cotidiano II. Habitar, cocinar. México: Universidad Iberoamericana.

De Certeau, Michel (2007). La invención de lo cotidiano I. Las artes de hacer. México: Universidad Iberoamericana.

Debord, Guy (1999). La sociedad del espectáculo. Madrid: Pre-textos.

Deleuze, Gilles (1987). Foucault. Buenos Aires: Paidós.

Deleuze, Gilles (1995). Conversaciones. Valencia: Pretextos.

Deleuze, Gilles y Foucault, Michel (2005). Un diálogo sobre el poder y otras conversaciones. Madrid: Alianza.

Duncan, James (2007). In the shadows of the tropics. Climate, race and biopower in nineteenth century Ceylon. London: Ashgate.

Escobar, Arturo (2005). “El 'postdesarrollo' como concepto y práctica social". En: Daniel Mato (coord.) Politicas de economía, ambiente y sociedad en tiempos de

Revista ESPIGA Año XIV, N. ${ }^{\circ}$ 29:55-70, enero-junio 2015 
globalización (pp. 17-31). Caracas: Universidad Central de Venezuela.

Esposito, Roberto (2006). Bíos. Biopolitica y filosofía. Madrid: Amorrortu Editores.

Fernández, Óscar (2000). "Poder". En: Diccionario Electoral, Tomo II (pp. 1000-1007). San José: Instituto Interamericano de Derechos Humanos.

FERnÁNDEZ, Óscar (2002). "Weber y Foucault". Reflexiones, 81(2): $36-41$

Foucault, Michel (1979). Arqueología del saber. México: Fondo de Cultura Económica.

Foucault, Michel (1980). El ojo del poder. Entrevista con Michel Foucault. En: Bentham, Jeremías. El Panóptico (trad. Julia Varela y Fernando Alvarez-Uría). Barcelona: La Piqueta.

Foucault, Michel (1986). "Of others spaces". En: Diacritics, 22-27.

Foucault, Michel (1988). "El sujeto y el poder". En: Revista Mexicana de Sociología, 3(1): 15-34. México.

Foucault, Michel (1993). Microfisica del poder. Barcelona: La Piqueta.

Foucault, Michel (1996a). Historia de la sexualidad III. México: Siglo XXI Editores.

Foucault, Michel (1996b). La verdad y las formas jurídicas. Barcelona: Gedisa.

Foucault, Michel (2000). El orden de las cosas. Barcelona: Tusquets.

Foucault, Michel (2001). Defender la sociedad: Curso en el Collège de France (1975-1976). México: Fondo de Cultura Económica.

FouCAult, Michel (2002). Vigilar y castigar: nacimiento de la prisión. México: Siglo Veintiuno.

Foucault, Michel (2005). Un diálogo sobre el poder y otras conversaciones. Madrid: Alianza Materiales.

Foucault, Michel (2007). Nacimiento de la Biopolítica. Buenos Aires: Fondo de Cultura Económica.

Foucault, Michel (2008). Seguridad, territorio y población. Buenos Aires: Fondo de Cultura Económica.

Foucault, Michel (2009). Historia de la sexualidad I. La voluntad de saber. México: Siglo XXI.

García Canal, María (2006). Espacio y poder. El espacio en la reflexión de Michel Foucault. México: Universidad Autónoma Metropolitana.
García, María (2009). "Poder”. En: Szurmuk, Mónica y Mckee Irwin, Robert (Coord.). Diccionario de estudios culturales latinoamericanos. México: Siglo XXI.

Giavedoni, José (2012). "Resistir en la tierra del panoptismo. Esbozo en torno al problema de las relaciones de poder y las resistencias desde una perspectiva foucaultiana”. Tabula Rasa, 16(1): 243-261.

Gibson-Graham, J. K. (2002). "Intervenciones posestructurales". Revista Colombiana de Antropología, 38(1): 261-286.

Giorgi, Gabriel y Rodríguez, Fermín (Comp.) (2007). Ensayos sobre biopolítica y excesos de vida. Buenos Aires: Paidós.

GiRALDO, Reinaldo (2009). "La ética en Michel Foucault o de la posibilidad de la resistencia”. Tabula Rasa, 10(1): 225-241.

Hindess, Barry (1996). Discourses of Power: from Hobbes to Foucault. Oxford: Blackwell.

HobBes, Thomas (1987). Leviatán. México: Gernika.

IBARRA, Jorge (2008). Foucault y el poder. Diatriba al Derecho, la Razón de Estado y los aparatos disciplinarios. Valparaíso: Manuscrito.

Kapferer, Bruce (2007). "Poder". En: Barfield, Thomas (edit.). Diccionario de Antropología (pp. 408-410). México: Siglo XXI.

Lemm, Vannesa (Edit.) (2010). Michel Foucault: Neoliberalismo y biopolítica. Santiago de Chile: Editorial Universidad Diego Portales.

Levi-Strauss, Claude (1977). Antropología estructural. Buenos Aires: Eudeba.

Levi-Strauss, Claude (1998). Mitológicas I. Lo crudo y lo cocido. Buenos Aires: Fondo de Cultura Económica.

MoORe, Henrietta (2000). "Anthropological Theory at the Turn of the Century". En: Moore, Henrietta (edit.). Anthropological Theory Today (pp. 1-23). Cambridge: Polity Press.

ORTNER, Sherry (1984). "Theory in Anthropology since the Sixties". Comparative Studies in Society and History 26(1): 126-166.

Osorio, Jaime (2012). Estado, biopoder, exclusión. Análisis desde la lógica del capital. Barcelona: Anthropos.

Payne, Michel (2002). Diccionario de teoría crítica y estudios culturales. Madrid: Paidós.

Pedraza, Zandra (2004a). "Y el verbo se hizo carne... Pensamiento social y biopolítica en Colombia". En: Castro-Gómez, Santiago (ed.). Pensar el siglo XIX. Cultura, biopolítica y modernidad en Colombia (pp. 185-200). Pittsburg: Universidad de Pittsburg. 
PedrazA, Zandra (2004b). "El régimen biopolítico en América Latina. Cuerpo y pensamiento social". Iberoamericana 4(15): 7-19.

Rabinow, Paul (1984). The Foucault Reader. Pantheon Books.

Rabinow, Paul (2003). The Essential Foucault. The New Press.

Rabinow, Paul (2004). "Ordonnance, Discipline, Regulation: Some Reflections on Urbanism”. En: Low, Setha y Zúñiga, Lawrence (Edit.) The Anthropology of Space and Place: Locating Culture (pp. 353-361). Oxford: Blackwell.

Rabinow, Paul y Dreyfus, Hurbert (1988). Foucault. Más allá del estructuralismo y la hermenéutica. México: UNAM.

Raynaud, Philippe y Rials, Stephane (2001). Diccionario Akal de Filosofia Politica. Madrid: Akal.

Restrepo, Eduardo (2004). Teorías contemporáneas de la etnicidad: Stuart Hall y Michel Foucault. Popayán: Editorial Universidad del Cauca.

Restrepo, Eduardo y Rojas, Axel (2010). Inflexión decolonial: fuentes, conceptos y cuestionamientos. Bogotá: Instituto de Estudios Sociales y Culturales Pensar, Universidad Javeriana.
Russell, Bertrand (1939). El poder en los hombres y en los pueblos. Buenos Aires: Losada.

SARDAR, Ziauddin (2005). Estudios culturales para todos. Barcelona: Paidós.

Scott, James (2003). Los dominados y el arte de la resistencia. Discursos ocultos. Mexico: Era.

SENNET, Richard (1999). Carne y piedra. Madrid: Alianza.

Stoler, Ann (1995). Race and the Education of Desire. Foucault's history of sexuality and the colonial order of things. Duke: Duke University Press.

Strathern, Paul (2014). Foucault en 90 minutos. México: Siglo XXI.

UgARTE, Javier (Comp.) (2005). La administración de la vida. Estudios biopolíticos. Barcelona: Anthropos.

Virilio, Paul (1999). La máquina de visión. Madrid: Cátedra.

Weber, Max (1979). Economía y Sociedad. México: Fondo de Cultura Económica.

Wright Mills, Charles (1980). La élite del poder. México: Fondo de Cultura Económica. 